\title{
Investigation of the Stability and Electronic Structures for Exohedral Aln Doped (Mono and Double)-Layer MgO Nanosheet s: A DFT Approach
}

\author{
Nibras Mossa Umran', Haneen Ali Rashed², Aseel Mustafa Abdul Majeed ${ }^{3}$, Gagandeep Kaur ${ }^{4}$ \\ ${ }^{1,2}$ Department of Physics, College of Science, University of Kerbala, Karbala, Iraq \\ ${ }^{3}$ Department of Physics, College of Science, University of Mustansiryah University, Baghdad, Iraq \\ ${ }^{4}$ Department of Applied Sciences, Chandigarh Group of Colleges-College of Engineering, Landran, Mohali, Punjab, India \\ Email: ${ }^{1}$ nibrasmossa@uokerbala.edu.iq
}

\section{ABSTRACT}

In present work, a detailed analysis of density functional theory (DFT) study performed on pure and doped MgO nanosheet(MgONs). The aim of this work is to explore the stability skeleton, and electronic properties of mono layer of the MgO nanosheets and analogous double-layers with various positions of exohedral $\mathrm{Al}_{\mathrm{n}}$ dopant atoms. Our results for pure and doped $\mathrm{MgO}$ nanosheet corroborate with previous theoretical and experimental data. Optimized structures of monolayer and analogous double-layers of $\mathrm{MgO}$ nanosheet (MgONs) result in stable 2-D configuration, especially on doping with large concentrations. It has been observed that the band gap decreases with the increase in concentration of doping while the electronegativity increases.

\section{Keywords}

DFT, MgO nanosheet, exohedral doped, electronegativity, hardness

Article Received: XX Xxx 2021, Revised: XX Xxx 2021, Accepted: XX Xxx 2021

\section{Introduction}

Nanomaterials have attracted a great interest for theoretical and experimental research due to their unique physical and chemical characteristics which depend on the shape and size of nanomaterials, like hardness with high conductivit, [1, 2]. One of the important nanomaterial is Magnesium oxide, which is a famous simple oxide with rock salt structure in bulk phase. The 2D-MgO with both polar (111) and nonpolar (001) orientations have been successfully grown on various substrates experimentally [3-10]. This leads to the possibility of changing the electronic structure through doping which has recognized as a favorable alleyway to tune the properties of oxide materials toward the demands of different physics and chemistry applications. Dopants are supposed to disturb the lattice structure locally by breaking bonds to nearby atoms. As a consequence, interatomic coupling gets [11]. Density functional theory (DFT) study for electronic calculations of $\mathrm{MgO}$ mono-layer have also shown to display a more fascinating feature than its bulk phase for instance shrinking the band gap from $7.8 \mathrm{eV}$ to 3.1 $\mathrm{eV}$ (for GGA) and $4.2 \mathrm{eV}$ (for GGA-mBJ) [12]. The DFT calculations of $\mathrm{Cr}$ doped Rocksalt $\mathrm{MgO}$ reveal that $\mathrm{CrMg} 3 \mathrm{O} 4$ is a promising spintronic material due to its half-metallic ferromagnet property as well as its resistivity to deform due to the large bulk modulus and shear modulus [13].

Fascinated by the interesting properties of doped MGO NSs, we perform density functional theory (DFT) to examine the stable structure, and electronic properties (binding energy, ionization potential, electron affinity, electronegativity and hardness) of hexagonal MgO NSs (111) after exohedral doping by $\mathrm{Al}_{\mathrm{n}}$. Three geometries i.e mono layer of $\mathrm{MgO} \mathrm{NSs}$ in first and second case, and two layers of MgONs in the third case have been considered for investigation.

\section{Computational Approach}

$\mathrm{Ab}$ initio calculations in this study have been performed using the Spanish initiative for electronic simulations with thousands of atoms (SIESTA) program package $[14,15]$ which implements density functional theory (DFT) using exchange correlation functional of generalized gradient approximation (GGA) [16,17] and utilizing the double zeta basis (DZ) to exhibit spin polarization [18]. The pseudo-potential standards are built by using Trouiller- Martins schemes which are described as the interaction of valence electrons with atomic central. Pseudopotentials with $2 s^{2} 2 p^{6} 3 s^{2}$ and $3 s^{2} 3 p^{1}$ valence electron configurations were used for $\mathrm{Mg}, \mathrm{O}$, and $\mathrm{Al}$ 
atoms, respectively. Conjugate gradient (CG) algorithm is used to get optimized structures of $\mathrm{MgO}$ NSs. The positions of all atoms are allowed to fully relax until the force on each atom is less than $0.008 \mathrm{eV} / \AA$ during relaxation. The energy cut-off of 200Ry has been used to define the finite real space grid for numerical integrals.

\section{Results and Discussion}

\subsection{Doping of $\mathrm{Al}_{\mathrm{n}}(\mathrm{n}=1-7)$ on single layered MgO NS:}

We start by investigating a pure $\mathrm{MgO}$ NSs by optimizing it with the atomic structure focused along either the (100) or (111) direction.The lattice constant for the optimized $\mathrm{MgO} \mathrm{NSs}(100)$ and the $\mathrm{MgO}$ NSs (111) obtained were 3.85 and $3.18 \AA$ respectively which are in good agreement with the previous results (4.01 and $3.26 \AA$ )[1922]. Also, the resulting $\mathrm{Mg}-\mathrm{O}$ bond length of optimized pure $\mathrm{MgO}$ (111) NSs comes out to be $1.99 \AA$ with bond angles between $\mathrm{Mg}-\mathrm{O}-\mathrm{Mg}$ bonds equal to $120^{\circ}$ which is comparable to formerly obtained results [7,21] as shown in Fig.1. Further on comparing the binding energies of both structures, it was found that, the binding energy of the optimized $\mathrm{MgONs}(111)$ system decreases by about $0.28 \mathrm{eV}$ per $\mathrm{Mg}-\mathrm{O}$ pair, which indicates that this $\mathrm{MgONs}(111)$ is more stable than the MgONs(100).

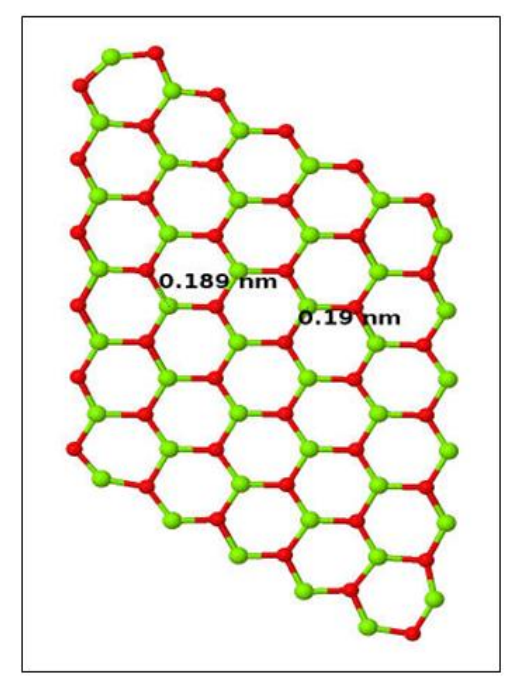

Fig.1: Optimize structure of MgO NSs pure, the green and red spheres refer to Magnesium and Oxygen atoms respectively.

After optimization of the pure hexagonal $\mathrm{MgO}$ NSs, we perform a full geometry optimization of $\mathrm{Al}_{\mathrm{n}}(\mathrm{n}=1-6)$ exohedral doped MgO NSs. The atomic configurations for the $\mathrm{Al}$ doped $\mathrm{MgO} \mathrm{NSs}$ are shown in Fig.2. The bond length obtained between the dopant $\mathrm{Al}$ and it nearest $\mathrm{Mg}$ atom (Al-Mg distance) is $2.6 \AA$, while $\mathrm{Al}-\mathrm{O}$ bond length comes out to be $2.38 \AA$ [23]. Also, we observe that the dopant $\mathrm{Al}$ atom is still in the same plane as the $\mathrm{Mg}$ and $\mathrm{O}$ atoms causing strain into the lattice of the $\mathrm{MgO}$ NSs.
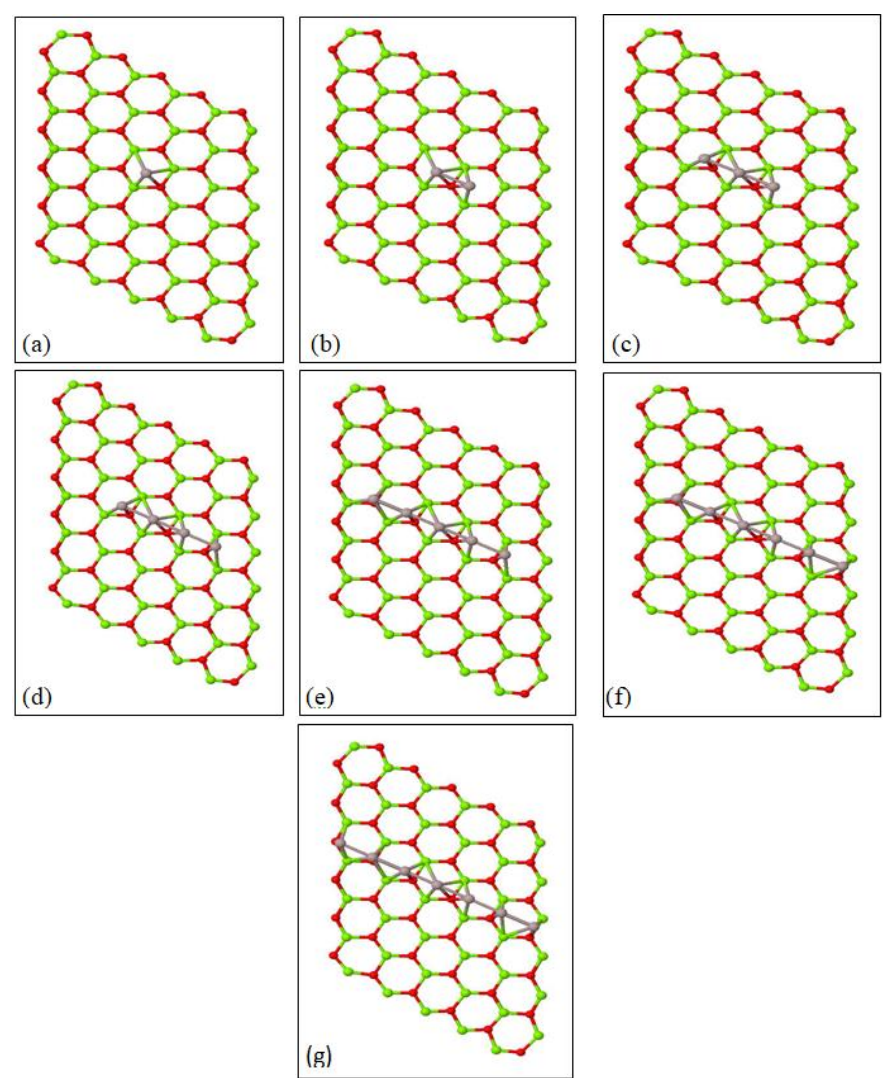

Fig.2(a-g): Optimize structure of $\mathrm{Al}_{\mathbf{n}}(\mathrm{n}=1-7)$, the green, red, and gray spheres refer to magnesium, oxygen, and the aluminum dopant atoms respectively.

Figure 2:For the optimized doped structures, the binding energy per atom $\left({ }^{E_{b}}\right)$ of the doped systems has been calculated to evaluate their stability by using the equation[19]:

$E_{b}=\left(E_{m M g o}-E_{M g o}-n E_{m}\right) / N$

Where, ${ }^{E_{m M g o}}$, and $E_{\mathrm{Mgo}}$ are total energies of the $\mathrm{Al}$ doped $\mathrm{MgONs}$ and the pristine $\mathrm{MgO} \mathrm{NS}$, respectively, while $\mathrm{n}$ represent the number of dopant, $E_{m}$ total energy of the $\mathrm{Al}$ dopant and N is the total number of atoms in a supercell $(n=82)$.

A negative value of binding energy corresponds to a metastable or stable bound dopant when both are present in the system[22]. The variation of binding energy per atom for doped $\mathrm{MgO} \mathrm{NS}$ is 
shown in Fig.3. It is clear from Fig. 3 that with the increase in the number of $\mathrm{Al}$ dopants, the binding energy of the $\mathrm{MgO}$ NS attains its maximum value at $-17.4 \mathrm{eV}$ for $\mathrm{Al}_{7}$. The binding energy oscillates for $\mathrm{Al}_{4}$ for $\mathrm{Al}_{6}$ dopants. From the structural analysis, it is found that the stability of $\mathrm{MgO} \mathrm{NS}$ strongly depends upon the number of dopant atoms in the sheet.

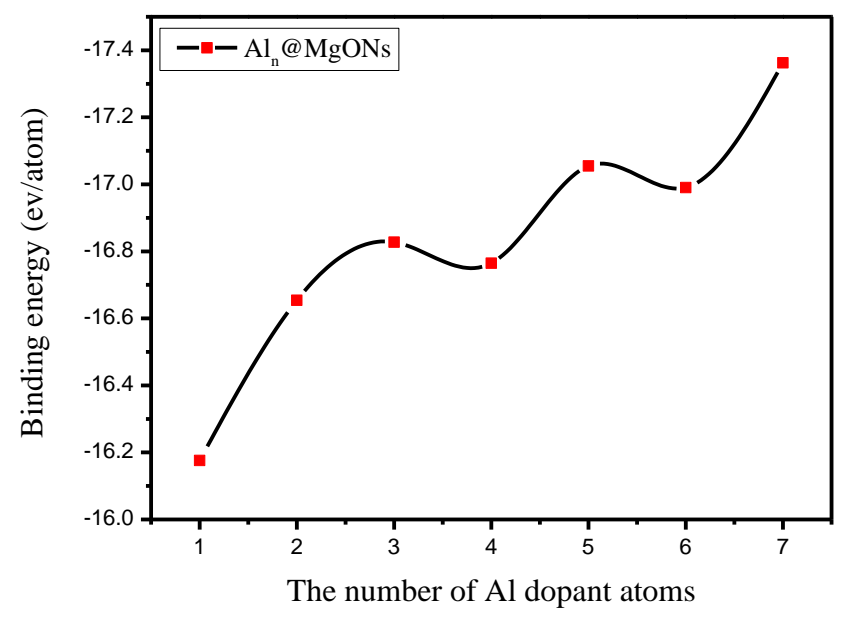

Fig.3: Binding energy per atom of variation Aln@MgO NS with a number of dopants (n=17).

The energy gaps of $\mathrm{Al}_{\mathrm{n}} @ \mathrm{MgO} \mathrm{NS}$ are lesser than that of the related $\mathrm{MgO} \mathrm{NS}$ and they depend on the type of dopant, number of dopants as shown in Fig.4. The band gaps for $\mathrm{Al}_{\mathrm{n}} @ \mathrm{MgO} \mathrm{NS}$ were calculated from highest occupied molecular orbital (HOMO) and the lowest unoccupied molecular orbital (LUMO) play a very important role[24]. The gap between HOMO and LUMO energy levels can be used to measure the kinetic stability of system under consideration. Larger the HOMO-LUMO gap, Larger will be the kinetic stability as it is energetically not favorable to add electrons to a high lying LUMO or to remove electrons from a low-lying HOMO.

Further, we notice that the doping with $\mathrm{Al}_{4}, \mathrm{Al}_{5}$, and $\mathrm{Al}_{7}$ are found to decrease the bandgaps of the $\mathrm{MgO}$ NS with increase the number of dopant. It is observed that the increase of the bandgap of the $\mathrm{MgO}$ with the decrease of the number of dopant[25]. This indicates that as the number of dopant increases, calculations show that all cases of $\mathrm{Al}_{\mathrm{n}} @ \mathrm{MgO} \mathrm{NS}$ display semiconducting behavior and the $\mathrm{Al}_{\mathrm{n}} @ \mathrm{MgO}$ NS becomes energetically favorable.

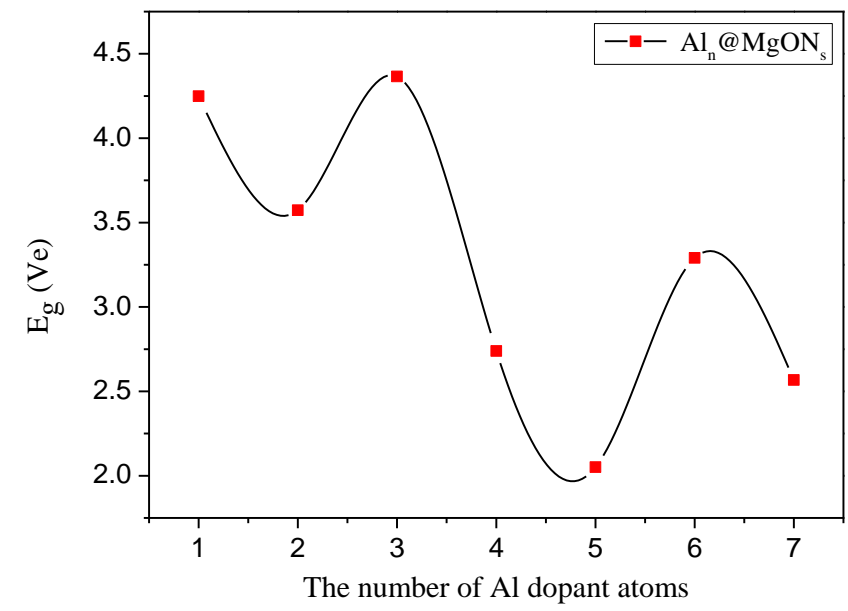

Fig.4: The band gaps of $\mathrm{Al}_{\mathrm{n}} @ \mathrm{MgO} \mathrm{NS}(\mathrm{n}=1-7)$ in $\mathrm{eV}$.

We have calculated the ionization potential (IP) by making nanosheet of $\mathrm{Al}_{\mathrm{n}} @ \mathrm{MgO}$ one electron deficient. Total energy for $\mathrm{Al}_{\mathrm{n}} @ \mathrm{MgO} \quad \mathrm{NS}$ complex is computed and then the total energy of neutral $\mathrm{Al}_{\mathrm{n}} @ \mathrm{MgO} \mathrm{NS}$ is subtracted from it [26]. In the similar manner, electron affinity (EA) is calculated by putting one extra electron in neutral $\mathrm{Al}_{\mathrm{n}} @ \mathrm{MgO} \mathrm{NS}$ and computing the total energy for the same and then subtracting the total energy of neutral $\mathrm{Al}_{\mathrm{n}} @ \mathrm{MgO} \mathrm{NS}(\mathrm{n}=1-7)$ [26,27]. It is clear that, exohedral doping of $\mathrm{MgO}$ NS effects EA more than that of IP. IP is independent on the postion of the atom, but in case of $n=7$ the structure has higher IP, as illustrated in Fig.5. While the calculated EA of the studied structures is of the order of $n=1-7$. At the same time, this structure has the higher value of electron affinity EA. It is clear from the graphs shown in figure 5 that the $\mathrm{MgO} \mathrm{NS}$ doped with $\mathrm{Al}$ atoms have higher values of IP and EA than that of the original $\mathrm{MgO} \mathrm{NS}$. That means, these structures have high ability to accept electrons and become anions in comparison with $\mathrm{MgO}$ NS. However, they cannot easily donate an electron to the surrounding species. 

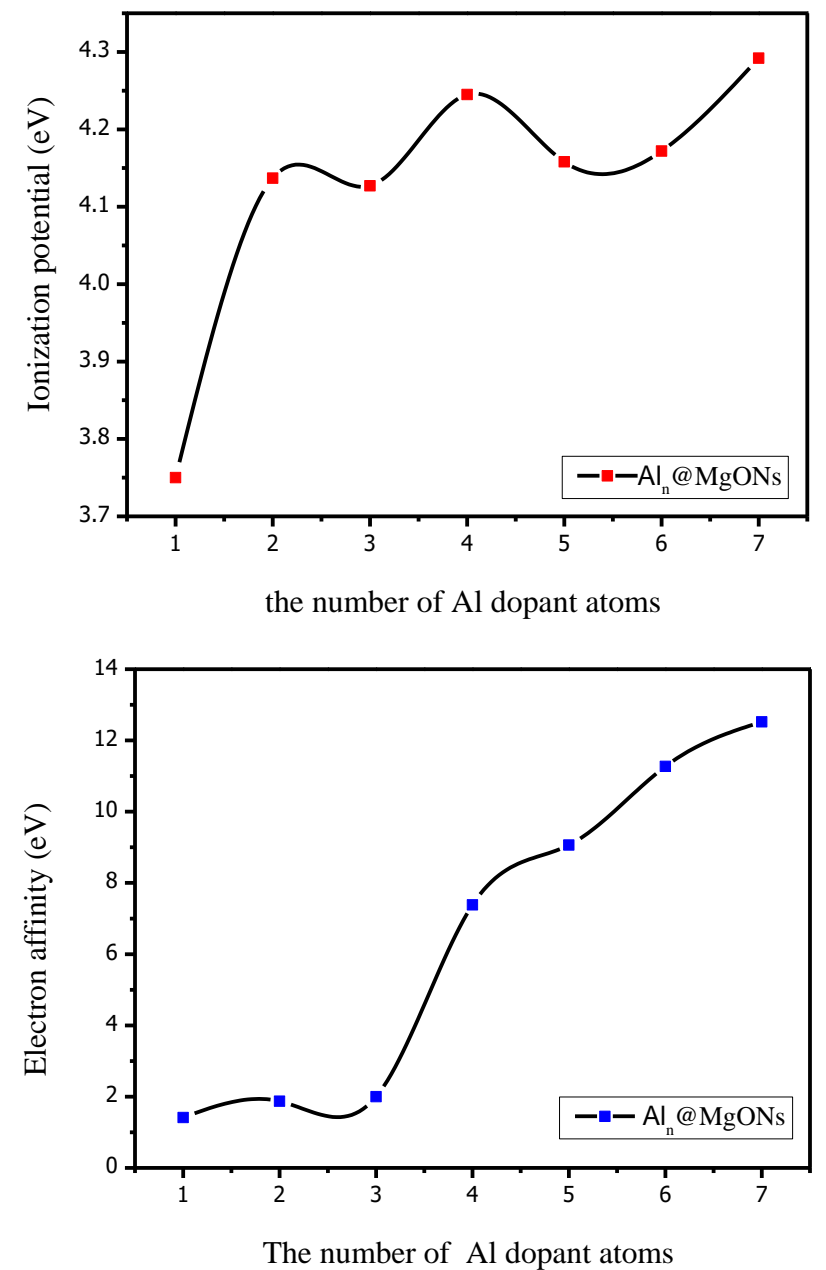

Fig.5: (a) The ionization potential and (b) electron affinity of $\mathrm{Al}_{\mathbf{n}} @ \mathrm{MgONs}(\mathrm{n}=1-7)$ in $\mathrm{eV}$.

Next, we obtain the electronegativity (EN) which is a linear combination of two known physical quantities i.e. ionization energy and electron affinity and is expressed as [20]:

$$
E N=(I P+E A) / 2
$$

As discussed, the hardness $(\mathrm{H})$ is defined in terms of ionization energies and electron affinities, the hardness is half of the energy gap between two frontier orbitals [27]:

$$
H=I P-E A
$$
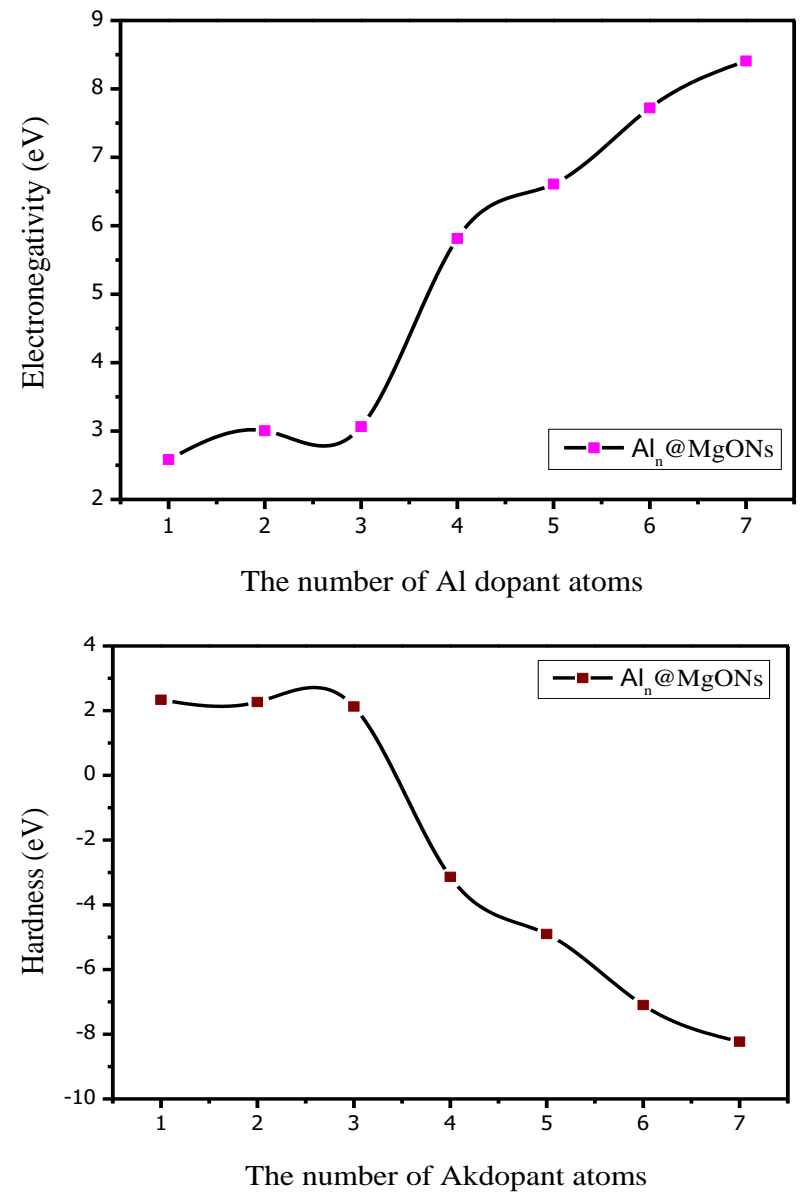

Fig.6: (a) The electronegativity and (b) hardness of $\mathrm{Al}_{\mathbf{n}} @ \mathrm{MgO} \mathrm{NS}(\mathrm{n}=1-7)$ in $\mathrm{eV}$.

According to Fig. 6(a), the behavior of the electronegativity (EN) is shown for $\mathrm{Al}$ exohedral doped in $\mathrm{MgON}_{\mathrm{s}}$. One can see that the addition of $\mathrm{Al}$ dopant atoms in $\mathrm{MgON}_{\mathrm{S}}$ leads to increase in the $\mathrm{EN}$ of the $\mathrm{MgON}_{\mathrm{S}}$, this may come from the variation in the electronegativity of $\mathrm{Mg}$ atoms $(1.3 \mathrm{eV})$ and $\mathrm{O}$ atoms $(3.5 \mathrm{eV})$. The influence of the hardness $\mathrm{H}$ is illustrated in Fig. 6(b). Except the $\mathrm{Al}_{7} \mathrm{MgO} \mathrm{NS}$ structure, all the other structures have higher values of $\mathrm{H}$ which means except $\mathrm{Al}_{7} \mathrm{MgO}$ NS, all other structures are more soft.

\subsection{Doping of $\mathrm{Al}_{14}, \mathrm{Al}_{28}$ and $\mathrm{Al}_{35}$ on single layered MgONs:}

As minor variations in the lattice parameters might suggest high solubility of $\mathrm{Al}$ in $\mathrm{MgO} \mathrm{NS}$, it refers to the extent of the impact the Al dopants on the $\mathrm{MgO}$ NS (and vice versa). The structural geometries of $\mathrm{Al}_{\mathrm{n}} @ \mathrm{MgO} \mathrm{NS}(\mathrm{n}=14,28$, and 35) are collected in Fig. 7. Whereas adopted equal the distance between lines of $\mathrm{Al}_{7-35}$ exohedral doped This means that $\mathrm{Al}_{28}$ is more strained on the surface $\mathrm{MgO} \mathrm{NS}$ than $\mathrm{Al}_{14}$, because of this 
$\mathrm{Al}_{28} @ \mathrm{MgO} \mathrm{NS}$ is more stable than $\mathrm{Al}_{14} @ \mathrm{MgO}$ NS. The average surface area to $\mathrm{Al}_{28} @ \mathrm{MgO} \mathrm{NS}$ are $7.190 \AA, 7.160 \AA$ and $\mathrm{Al}_{14} @ \mathrm{MgO} \mathrm{NS}$ are $7.190 \AA$, $7.176 \AA$. This means that the structure $\mathrm{Al}_{28} @ \mathrm{MgO} \mathrm{NS}$ is less distorted as relative to its peers.

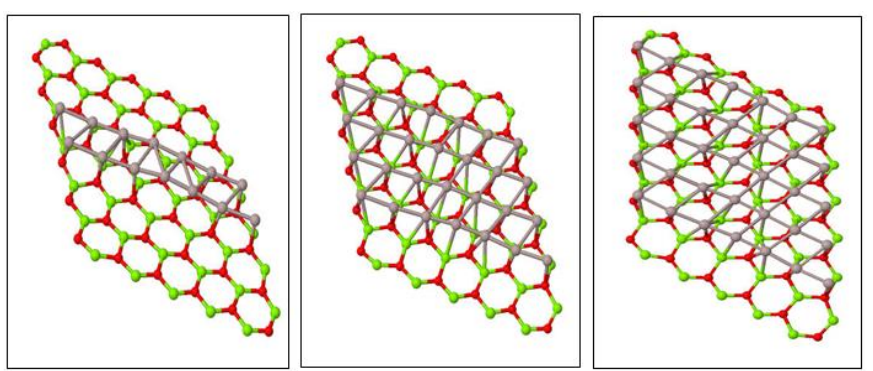

Fig.7: Optimized structures of Aln@MgONs $(\mathrm{n}=14,28$, and 35).

Also, variation of binding energy for Al-doped configurations for each doping concentration is represented in Fig.8. It is observed that the binding energy decreases with increase in concentration of dopants, indicating the decreasing structural stability as compared to the $\mathrm{Al}_{7} @ \mathrm{MgONs}\left(\mathrm{E}_{\mathrm{b}}=-17.40 \mathrm{eV}\right.$ per atom). This is due to the surface area to $\mathrm{MgO} \mathrm{NS}$ as well as the nearly similar size of the atomic radius of Aldoped which means there is lesser structural distortion.

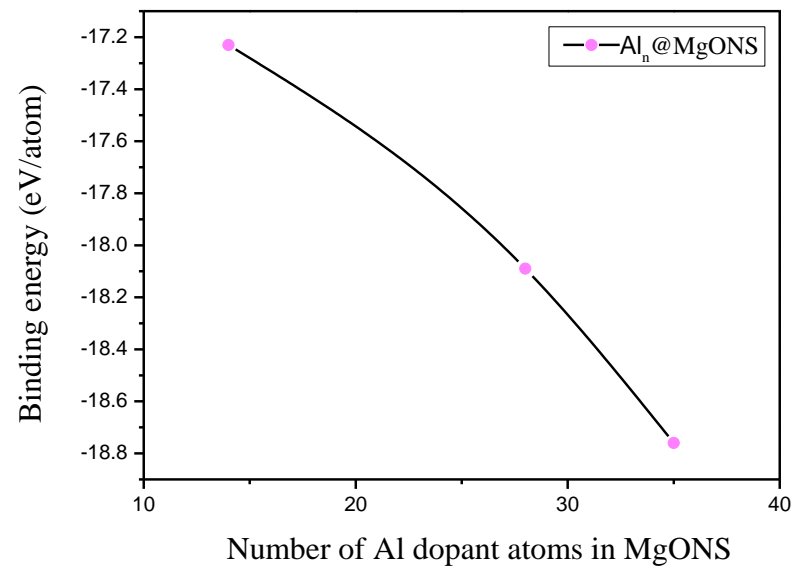

Fig. 8. Variation of binding energy with increasing concentration of $\mathrm{Al}_{\mathbf{n}} @ \mathrm{MgO} \mathrm{NS}$ $(n=14,28$, and 35) dopants.

The electronic structure analysis shows a narrowing of the band gap for higher dopant concentration, which shows the smallest band gap. A plot of the variation of band gap with doping concentration is shown in Fig. 9. Thus Al doping delivers a way to present a gap in $\mathrm{MgO}$ NS at the Dirac point to an important value without varying the unique properties of $\mathrm{MgO} \mathrm{NS}$.

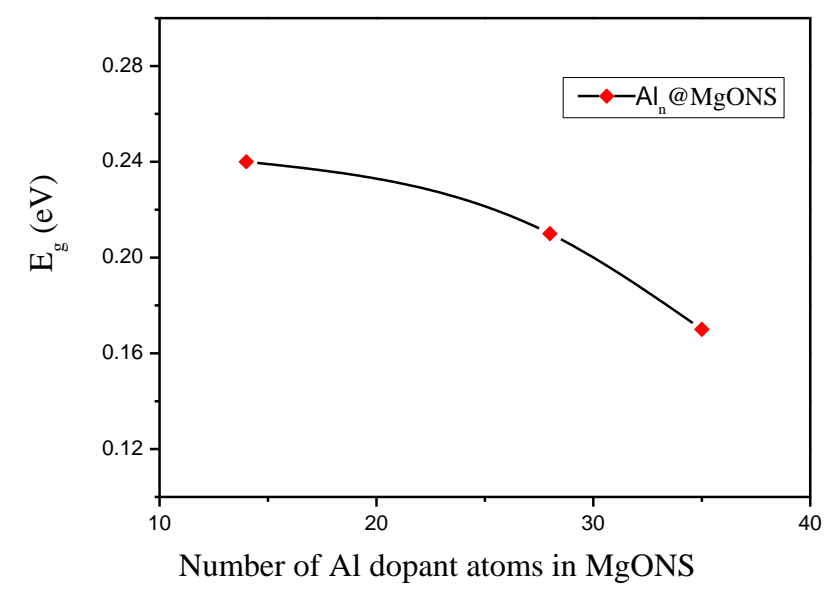

Fig. 9. The band gap with increase in doping concentration of $\mathrm{Al}_{\mathrm{n}}$ in $\mathrm{MgO} \mathrm{NS}(\mathrm{n}=14,28$, and 35).

On the other hand in Fig. 10(a), the ionization potential is less sensitive and increases exponentially with the increase in the concentration of $\mathrm{Al}$ doping to $\mathrm{MgO}$ NS structure. This indicates that the ionization potential does not show much dependence on the crystal structure of $\mathrm{MgO} \mathrm{NS}$. Also, it is independent of the width of the $\mathrm{MgO}$ NS. The structure $\mathrm{Al}_{35} @ \mathrm{MgO} \mathrm{NS}$ has higher ionization potential. This means that $\mathrm{Al}_{28} @ \mathrm{MgO} \mathrm{NS}$ need large energy to become cation as compared to the other two. Fig. 10(b) shows the calculated electron affinity of the structures Aln@MgO NS ( $\mathrm{n}=14,28$, and 35) increasing, That means these structures have a high ability to acceptance electrons and become anions, and in comparison with structure $\mathrm{Al}_{7} @ \mathrm{MgO} \mathrm{NS}$ they are cannot easily to donate an electron to the surrounding species.

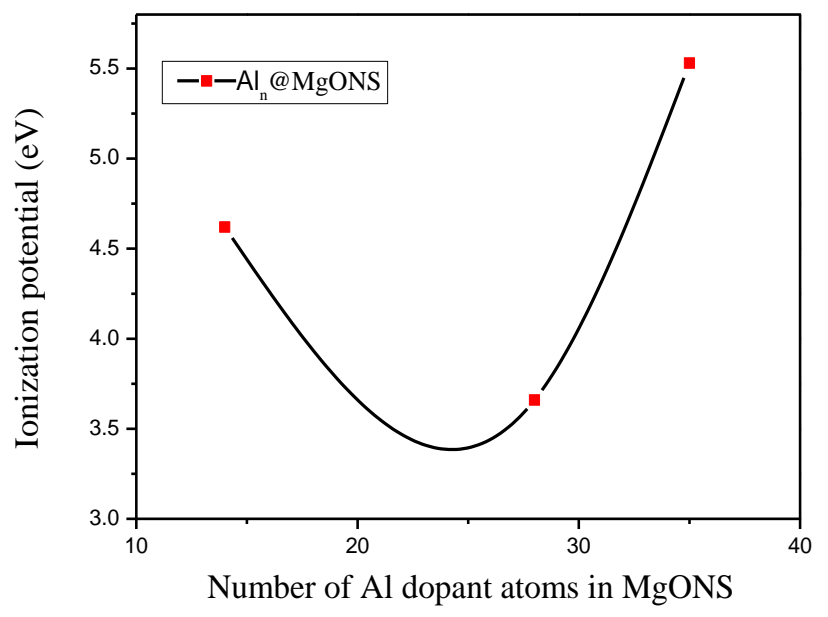




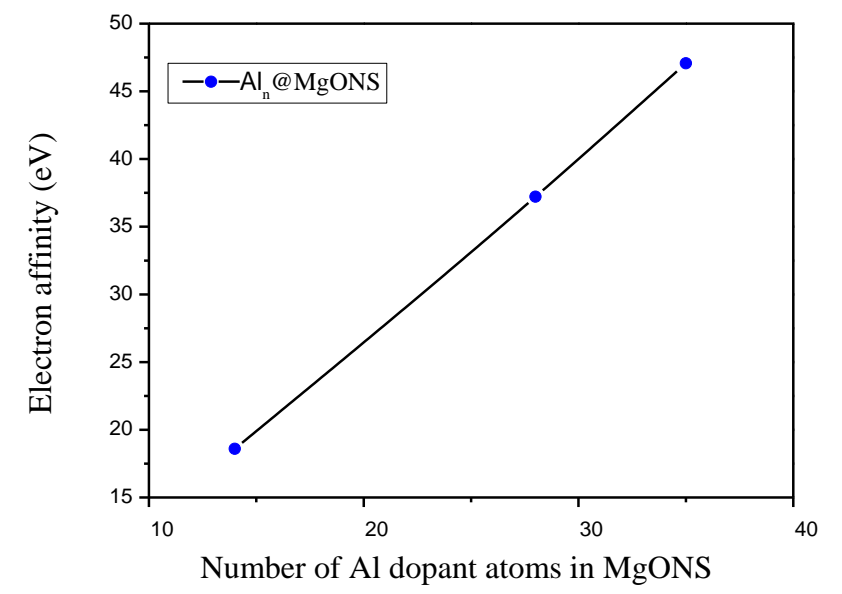

Fig. 10 (a): The ionization potential and (b) electron affinity in increasing order of doping concentrations $\mathrm{Al}_{n} @ \mathrm{MgO} \mathrm{NS}(\mathrm{n}=14,28$, and 35).

In order to study the influence of dopants on the electronic structures, the electronagtivity indices of $\mathrm{Al}_{\mathrm{n}} @ \mathrm{MgO} \mathrm{NS}(\mathrm{n}=14,28$, and 35) are evaluated and shown in Fig.11(a). It is obvious from the graph that electronagtivity increases as the $\mathrm{Al}$ content increases and can be related to the band gap narrowing with increase of the $\mathrm{Al}$ concentration. Fig.11(b) shows the electrochemical hardness of $\mathrm{MgO} \mathrm{NS}$, one can see, hardness decreases with the increase in the concentration of $\mathrm{Al}$ doping to the surface area of $\mathrm{MgO}$ NS. Eg equals to $0.21 \mathrm{eV}$ and $0.17 \mathrm{eV}$. Now, comparing with the structures in the first group, $\mathrm{Al}_{6} @ \mathrm{MgO} \mathrm{NS}$ and $\mathrm{Al}_{7} @ \mathrm{MgO} \mathrm{NS}$ have smaller values of hardness.

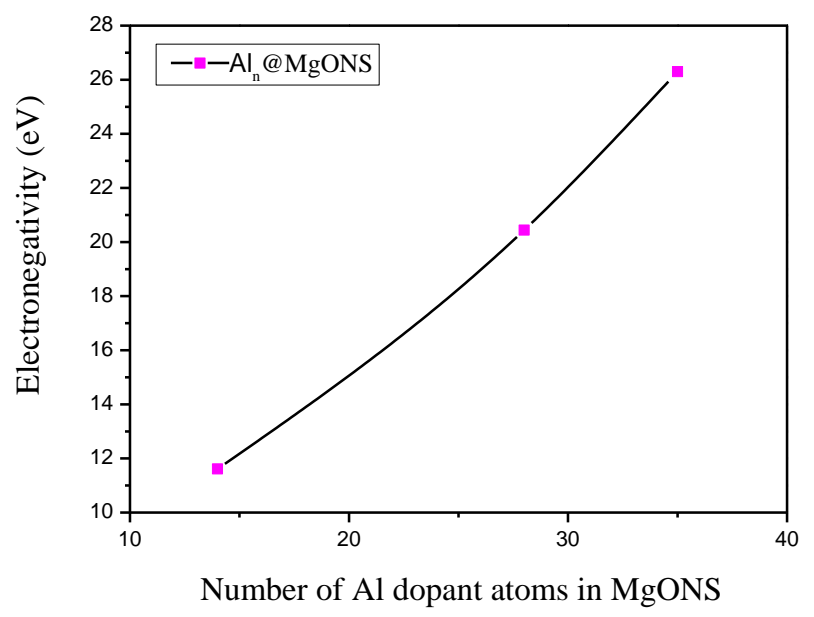

www.psychologyandeducation.net

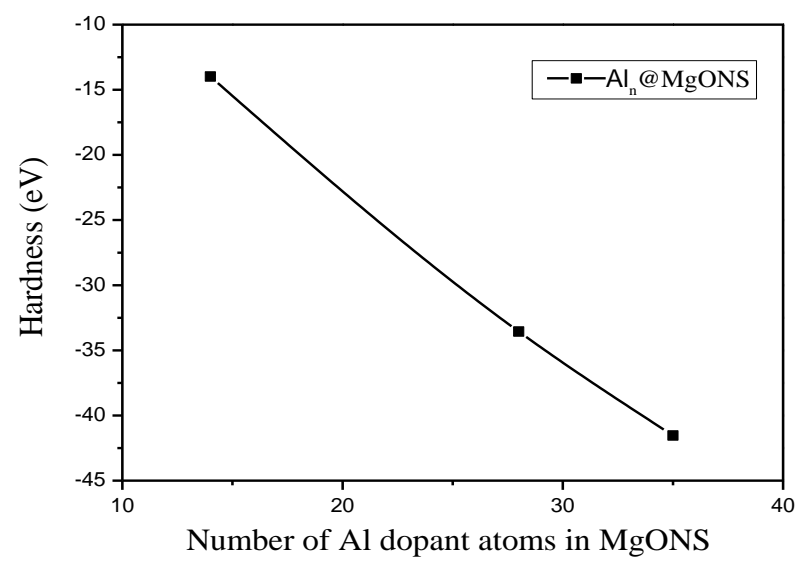

Fig. 11. (a): The electronagtivity and (b) hardness in increasing order of doping concentrations Aln@MgONs (n=14, 28, and 35).

\subsection{Doping of $\mathrm{Al}_{7}$ and $\mathrm{Al}_{35}$ on double layered MgO NS:}

In this step, the GGA calculations have been used to obtain optimized structures of two sheets of $\mathrm{MgO}$. As shown in Fig. 12, two layers of $\mathrm{MgO}$ contain sixty hexagons with the symmetry having the angles in hexagons between $3^{\circ}$ to $122.9^{\circ}$ [28]. The distance between the two layers are $2.98 \AA$ while two individual $\mathrm{Mg}-\mathrm{O}$ bonds are distinguished within the layers and another between a hexagon with average bond lengths of 1.88 and $1.95 \AA$, respectively. This indicates that the structure possesses a real fixed point on surface potential from 120. After that the two layers were doped by exohedral method. In the first case, the two layers were doped with seven $\mathrm{Al}$ atoms and the bond length between $\mathrm{Al}-\mathrm{Mg}$ was kept at about $2.68 \AA$. In the same manner, two layers were doped with thirty-five atoms of Al.
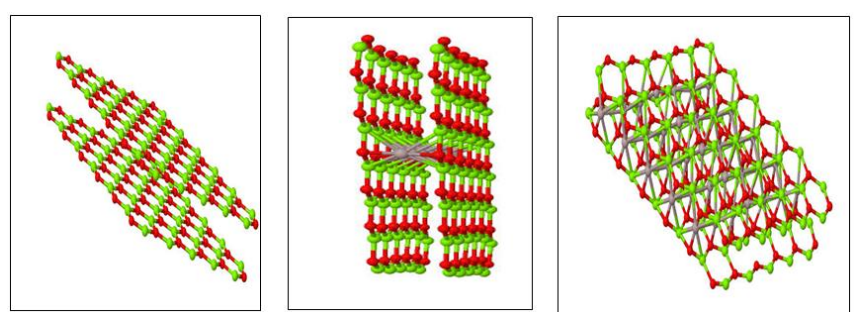

Fig.12: Optimized structures of pure double layered MgO NS and Aln@MgO NS(n=7 and 35).

We notice that as compared to the binding energy of the system with the one layer, here in this case, it increases by about $2.02 \mathrm{eV}$ for every $\mathrm{Mg}-\mathrm{O}$ pair 
and is more than the mono layer. Also, the binding energies increase with different numbers of doped $\mathrm{Al}$ atoms for the double layered $\mathrm{MgO}$ NS as shown in Table 1. One can see clearly that the band gaps of these doped structures of double layered $\mathrm{MgO}$ NSs are smaller than that of single layered $\mathrm{MgO} \mathrm{NS}$ and strongly depend on number of doped $\mathrm{Al}$ atoms[29]. For the case of $\mathrm{Al}=7$, the band gap is about $0.29 \mathrm{eV}$ and with increasing number of the $\mathrm{Al}$ i.e. 35 , the band gap increases and comes out to be $0.332 \mathrm{eV}$. To investigate the electronic properties, we have also calculated ionization potential, electron affinity, electronegativity and hardness of exohedral configurations. Also, we observe the changes in IP \& EA with exohedral doping of $\mathrm{MgONs}$ as mentioned in Table. The increase in IP\& EA with number doping atoms shows the high ability to accept electrons and become anions. The values of EN\& $\mathrm{H}$ corresponding to $\mathrm{n}=7$ and 35 of $\mathrm{Al}$ atoms indicate that they are more reactive with high values of electronegativity EN. All the other structures have smaller values of $\mathrm{H}$ in comparison with one layered doped $\mathrm{MgO}$ NS. This causes are more soft structure with small excitation energies than the original structure.

Table 1: Calculated Ionization potential (IP) and Electron affinity (AE) Electronegativity (EN) and Hardness (H) in eV for two layer, and Al doped MgONs.

\begin{tabular}{|lcccccc|}
\hline configurations & $\mathrm{BE}(\mathrm{eV} /$ atom $)$ & $\mathrm{E}_{\mathrm{g}}(\mathrm{eV})$ & $\mathrm{Ip}(\mathrm{eV})$ & $\mathrm{EA}(\mathrm{eV})$ & $\mathrm{EN}(\mathrm{eV})$ & $\mathrm{H}(\mathrm{eV})$ \\
\hline $2 \mathrm{MgONs}$ & -18.420 & 1.845 & 3.995 & 0.850 & 2.4225 & 3.145 \\
\hline $\mathrm{Al}_{7} @ \mathrm{Mg}_{82} \mathrm{O}_{82}$ & -19.316 & 0.297 & 3.351 & 0.053 & 1.702 & 3.298 \\
\hline $\mathrm{Al}_{35} @ \mathrm{Mg}_{82} \mathrm{O}_{82}$ & -20.698 & 0.332 & 3.411 & 0.079 & 1.745 & 3.332 \\
\hline
\end{tabular}

\section{Conclusions}

By using first principles calculations based on DFT, we study the stable structures and electronic properties by exohedral doping of $\mathrm{Al}$ atoms on the surface of $\mathrm{MgO}$ Ns. We find that $\mathrm{Al}$ atoms get adsorbed on flat $\mathrm{MgO}$ Ns walkways and monatomic steps, this is because the spin coupling Al-Al bond leads to a net stabilization which is not very affected by the strength of the $\mathrm{Al}$ bond during doping. Binding energy, between 16.2 and $17.4 \mathrm{eV}$ for all sites considered corresponds to a metastable. The band gaps for both $\mathrm{Al}_{\mathrm{n}} @ \mathrm{MgO} \mathrm{NS}$ NSs exhibit semiconducting properties, having band gaps between 0.45 and $0.20 \mathrm{eV}$ can be significantly tuned by their widths. Al:MgONs systems can be considered as potential material for applications in spintronics, solar energy applications and ultraviolet optielectronic devices.

\section{Acknowledgement}

Authors are grateful to the SIESTA group for providing their computational code and the authors would like to express their sincere appreciation to the Department of Physics, Science of college, Kerbala University, Karbala, Iraq.

\section{References}

[1] R. Wahab, et al., "Synthesis of magnesium oxide nanoparticles by sol-gel process," in Materials Science Forum, 2007, pp. 983-
986.

[2] L. Zhang, et al., "MgO nanosheet assemblies supported CoMo catalyst with high activity in hydrodesulfurization of dibenzothiophene," Industrial \& Engineering Chemistry Research, vol. 54, pp. 5580-5588, 2015.

[3] M. Kiguchi, et al., "Atomic and electronic structure of an unreconstructed polar $\mathrm{MgO}$ (111) thin film on $\mathrm{Ag}$ (111)," Physical Review B, vol. 68, p. 115402, 2003.

[4] R. Arita, et al., "Polar surface engineering in ultrathin $\mathrm{MgO}$ (111) Ag (111): Possibility of a metal-insulator transition and magnetism," Physical Review B, vol. 69, p. 235423, 2004.

[5] A. Del Vitto, et al., "Au atoms and dimers on the $\mathrm{MgO}$ (100) surface: a DFT study of nucleation at defects," The Journal of Physical Chemistry B, vol. 109, pp. 80408048, 2005.

[6] K. Zhu, et al., "Efficient preparation and catalytic activity of $\mathrm{MgO}$ (111) nanosheets," Angewandte Chemie International Edition, vol. 45, pp. 7277-7281, 2006.

[7] A. Akhtar, R. Pilevarshahri, and Mohammad Reza Benam," Investigating and comparison of electronic and optical properties of $\mathrm{MgO}$ nanosheet in (100) and (111) structural directions based on the density functional theory" Physica B 
502(2016) 61-67.

[8] M. Mantilla, et al., "Oxidation of $\mathrm{Mg} / \mathrm{Ag}$ (1 1 1) investigated using scanning tunneling microscopy: Towards atomically smooth $\mathrm{MgO}$ nanostructures," Surface science, vol. 602, pp. 3089-3094, 2008.

[9] K. Matsuzaki, et al., "Layer-by-layer epitaxial growth of polar $\mathrm{MgO}$ (111) thin films," Physical Review B, vol. 82, p. 033408, 2010.

[10] S. Benedetti, et al., "Competition between polar and nonpolar growth of $\mathrm{MgO}$ thin films on Au (111)," The Journal of Physical Chemistry C, vol. 115, pp. 23043-23049, 2011.

[11] S. Benedetti, et al., "Chromium-Doped $\mathrm{MgO}$ Thin Films: Morphology, Electronic Structure, and Segregation Effects," The Journal of Physical Chemistry C, vol. 119, pp. 25469-25475, 2015.

[12] Bromand Nourozia, Amin Aminian, Narges Fili, Yousof Zangeneh, Arash Boochani, and Pezhman Darabi, Results in Physics, vol.12, 2038-2043, 2019.

[13] Li-Jie Shi,First-principles prediction of the magnetism of $3 \mathrm{~d}$ transition-metal-doped Rocksalt MgO, Physics Letters A 374 (2010) 1292-1296

[14] E. Aratch, D. Sanchez-Potral, P. Orejon, A. Garcia, and J. M. Soler, Phys. Stat. Sol. (b), vol. 215, 809, 1999.

[15] Nibras Mossa Umran and Ranjan Kumar, Quantum Matter, vol4, 1-5, 2015.

[16] J.P. Perdew, K. Burke, M. Ernzerhof, Phys. Rev. Lett. vol. 77, 3865, 1996.

[17] Nibras Mossa Umran and Ranjan Kumar, Physica B, vol. 437, 47-52, 2014.

[18] Haneen Ali Rashed, Nibras Mossa Umran, Mater. Res. Express, vol. 6, 045044, 2019

[19] L. Giordano, et al., "Properties of $\mathrm{MgO}$ (100) ultrathin layers on Pd (100): Influence of the metal support," Physical Review B, vol. 67,p. 045410, 2003.

[20] J. Goniakowski, et al., "Using polarity for engineering oxide nanostructures: structural phase diagram in free and supported $\mathrm{MgO}$ (111) ultrathin films," Physical review letters, vol. 93, p. 215702, 2004.

[21] M. Yeganeh and F. B. Baghsiyahi, "Vibrational and Thermodynamical Properties of MgO Nanosheets of (111) and
(100) Facets by Density Functional Theory," Journal of Electronic Materials, vol. 48, pp. 3816-3822, 2019.

[22] Y. Zhang, et al., "Structural features and electronic properties of $\mathrm{MgO}$ nanosheets and nanobelts," The Journal of Physical Chemistry C, vol. 116, pp. 23130-23135, 2012.

[23] L. Giordano, et al., "Nucleation of $\mathrm{Pd}$ dimers at defect sites of the $\mathrm{MgO}$ (100) surface," Physical review letters, vol. 92, p. 096105, 2004.

[24] R. M. Martin, Electronic structure: basic theory and practical methods: Cambridge university press, 2004.

[25] D. Wu, et al., "Stabilizing graphitic thin films of wurtzite materials by epitaxial strain," Physical review letters, vol. 107, p. 236101, 2011.

[26] J. A. Santana, et al., "Structural stability and defect energetics of $\mathrm{ZnO}$ from diffusion quantum Monte Carlo," The Journal of chemical physics, vol. 142, p. 164705, 2015.

[27] R. Shankar, et al., "Calculation of ionization potential and chemical hardness: A comparative study of different methods," International Journal of Quantum Chemistry, vol. 109, pp. 764-771, 2009.

[28] D. A. Abanin, et al., "Spin-filtered edge states and quantum Hall effect in graphene," Physical review letters, vol. 96, p. 176803, 2006.

[29] Y.-W. Son, et al., "Energy gaps in graphene nanoribbons," Physical review letters, vol. 97, p. 216803, 2006. 